\title{
The Pedagogy of Higher Education: How to Evaluate the Quality of Training in Morocco to Improve it
}

\author{
https://doi.org/10.3991/ijep.v8i1.7984 \\ Sara Riahi $\left.{ }^{(}\right)$, Azzedine Riahi \\ Chouaib Doukkali University, El Jadida, Morocco \\ riahisaraphdgmail.com
}

\begin{abstract}
This paper is devoted to the profession of higher education. It aims to characterize the profession of teaching and objectively draw the portrait of the Moroccan teacher to identify the business improvement routes, so the education system. This paper deals with the teaching profession in all cycles of education and training: a detailed analysis of the state of the trade is proposed for primary and secondary education, supplemented by the results of the survey, opinion on these cycles; for higher education and vocational training, a brief description of the state of business is provided in this paper.
\end{abstract}

Keywords-Higher Education, pedagogy, skills, scientific research, Morocco

\section{Introduction}

The educational issue seems currently given to the forefront of concerns of educational environments in higher education. Indeed, in recent years, many writings, symposia or congresses have had as subject the university pedagogy. And it is no coincidence that many stakeholders see in the provision of educational acts one of the major challenges of higher education. The Council itself has recently reminded us that: National Center of Scientific and Technical Research (CNRST), pedagogy and at the university, the valorization of the teaching function is important issues for tomorrow [1]. Recognizing that education is a major challenge for higher education, the Council has asked the Commission for Higher Education to explore it, to identify the educational requirements has the mission of training the higher education, specify the axes of a significant educational practice and rooted in the specific situation in higher education, to question the roles of the actors involved and to identify the most favorable institutional conditions in pedagogy. Pedagogy, which appears here as one of the major challenges of higher education can be defined as the process of helping in some social and institutional conditions, the student and the student to learn and grow [2] . This definition, which can be verified in terms of its exploratory and heuristic value in the following pages, contains, at the very least, four elements which combine the observations and reflections which constitute the main points of the present opinion. The first element concerns the very aim of the pedagogical act, namely the fact that the student learns and develops. This is, ultimately, the heart of the training mission, 
Paper-The Pedagogy of Higher Education: How to Evaluate the Quality of Training in Morocco to ...

which contains, for the university, the requirements for teaching in higher education, basic training, the program approach and research. This is the purpose of our paper

\section{The pedagogy of higher education}

Higher education institutions have a training mission that should be remembered, not so much to analyze it in itself as to show its implications for pedagogy. It is therefore from the pedagogical point of view, as defined above, that one looks at the mission of training higher education, which combines fundamental training and specialization, is expressed in the training programs, opens up research activities [3]. This article has four sections. The first describes the common mission of higher education of CNRST and universities and shows the need for inseparable competences among teachers. The second outlines the main components of basic training and explains the proper educational issues. The third focuses on the curriculum and the program approach that puts more and more forward to higher education and identifies the educational implications of this approach. The fourth relates to research and explains what can be pedagogy of the training of researchers [4]. The CNRST and the university share a common mission of higher education. This means that they also share common requirements for the educational act. In a quite appropriate sense, one can therefore speak of pedagogy of higher education which takes root in the missions of university training.

\subsection{The common higher education mission}

The CNRST and the university have a common mission of higher education. The discussion and analysis contained in a previous Council opinion, based on a report by the Committee on Higher Education and which implicitly laid down the anchors of this document, should not be repeated here. There are historical, legislative, administrative and pedagogical roots which undoubtedly invite us to consider that CNRST shares with the university a common mission of higher education. Suffice it to recall that the creation of the CNRST is interpreted as an original version of a vast movement aimed at providing post-secondary education shorter than university education, capable of preparing for the performance of higher-level technical functions, is the professional component of the mission of the CNRST and called a short higher education. On the other hand, we are also thinking more and more, and this joins the preuniversity component of the CNRST mission; that CNRST and university should be considered as two institutions which, in common and in continuity, administer a long training program, which ideally belongs to a single curriculum of higher education. Specifically, the mission of higher education is expressed in the fundamental training concepts, general education and specialization [5].

In fact, it is indeed a balance between these elements of formation. And it is a dynamic equilibrium, indeed, since higher education ultimately aims at access to a specialization, but a specialization that allows us to situate a field of disciplines in relation to all the universes of knowledge and which attaches to the very foundations of 
this discipline. But specialization lies precisely in the mastery of a discipline; general education, in the capacity to relativize this discipline and situate it in relation to all the universes of knowledge and the major fields of culture; and basic training in the appropriation of ideological, historical and methodological of this discipline. It is understood that the equilibrium of the elements is dynamic and that their dosage can and must vary, depending on whether it is pre-university training or technical training at CNRST, the first, second or third cycle at university [2].

The mission of higher education is also expressed in the concepts of teaching, research and service to the community. Of course, whether it is a question of one or the other of these functions, it is ultimately training. And the university is called to consolidate the achievements of college education, both in the pursuit of its own objectives and in a spirit of teaching inter-orders collaboration. Here, too, there are variable equilibrium, particularly between teaching and research, at both levels of education. The three functions are therefore fulfilled differently, depending on whether they are the CNRST or the university [3].

For example, at the second and third university levels, research are inextricably linked to education, with the training of the student being pursued in both research and teaching [4]. And while the research mission is not formally enshrined in the College Act, research does exist in college not only as a tool for collective development, but also as a tool for training high school students. If the high research potential of college professors is to be more widely recognized and used in the future, it is expected that the teaching function will be more valued and supported at the university level. There is, in fact, only one mission of higher education, but there are specificities which must be recalled briefly.

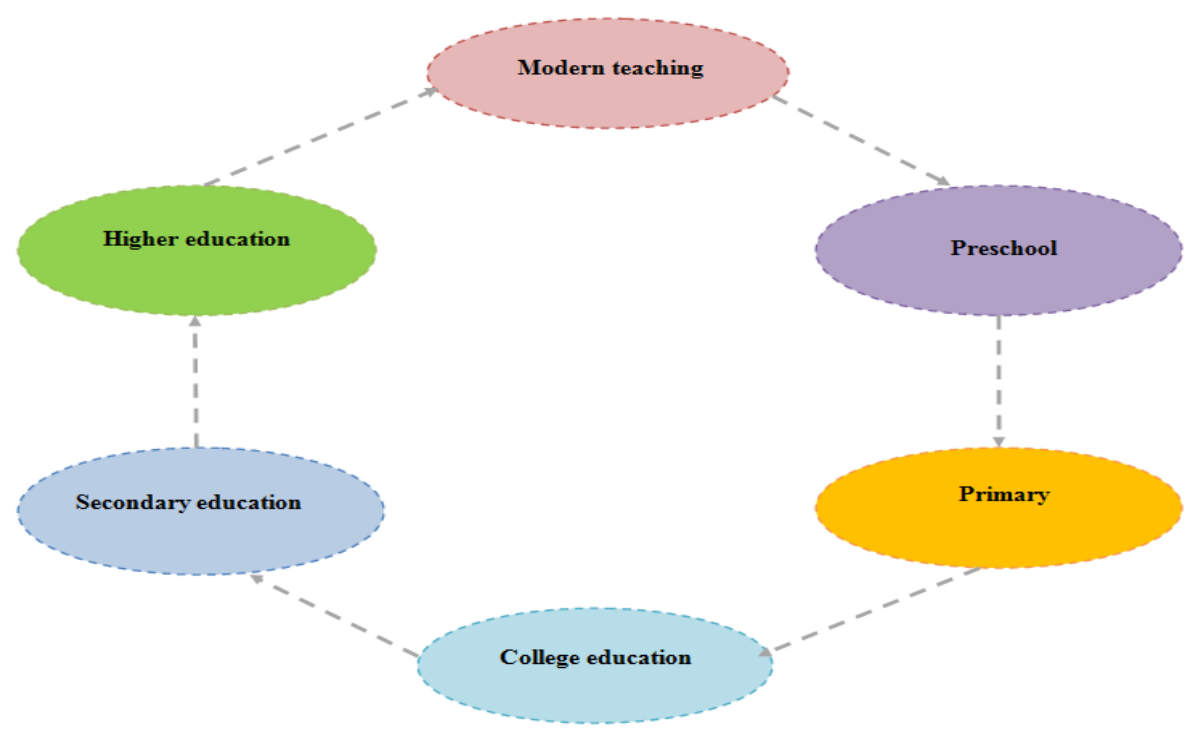

Fig. 1. The education system in Morocco includes pre-school, primary, secondary and university education. 
Thus, the technical college sector is clearly a specialization, normally distributed over three years of study. But this specialization includes general education components, the range of mandatory and additional courses underway and must be pursued in the context of fundamental education, appropriation disciplinary foundations, which can contribute to the so-called course 'of service'. Certainly, because of the immediate goals for the preparation for the labor market, one finds there a concern greater acquisition of knowledge and specific skills. But overall, and the employment market itself requires it, the prospect of a non-specialized, broadly versatile and foundational training is still paramount.

The pre-university college sector, as the name suggests, essentially pursues the goal of preparing for university studies. It therefore normally has the function of enabling the continuation of studies. It is also in the perspective of a fundamental formation that the student, choosing a concentration, is initiated into a field of knowledge. He must also follow and pass compulsory courses and complementary courses, which keep open the perspective of general education. The pre-university levels have the character of an initiation set of disciplines. In fact, the student is precisely in a field of disciplines, which he frequents, that are at least the ideal more and more asserts, from a fundamental training perspective [1].

It familiarizes them with an area of knowledge that normally close to his heart; it performs its first explorations and his first systematic research. Undergraduate studies are also geared towards specialization. But it is more and more from a basic foundation point of view that it is sought to define it, rather than in the still too much accentuated perspective of a disciplined disciplinary specialization at the present moment. The undergraduate student gradually introduces the language and methods of the discipline he has chosen, but we want more and more he does so from the perspective of fundamental training and by providing openings cultural aspects of general education. Already, however, he can practice systematic disciplinary research. But it's really the second and third university cycles the student, enjoying greater autonomy and more responsibility continues needing specialized vocational training or his research training in a discipline. At this stage, training is therefore acquired both by teaching and research. In other words, teaching and research are aimed at both the formation of a specialist, able to apply its specialized knowledge in a professional, the training of a researcher, able to produce itself new knowledge in his discipline

\subsection{Inseparable skills}

This broad mission of higher education imposes on the educators concerned a fourfold competence, which it seems increasingly impossible to disentangle: it concerns cultural, disciplinary, didactic and pedagogical competences. If one of them is missing, this is obviously the training described in the student may suffer, it goes without saying. First, cultural competence. In higher education, the pedagogue must obviously possess that cultural competence, which resides both in an intelligent opening to the various fields of ever-changing knowledge; arts, literature, natural sciences, humanities, technology and in a capacity to criticize all cultural production. The cultivating educator is therefore the one who bears witness to a real appropriation of various 
fields of knowledge and a distancing which allows him to judge the relativity of each and even to situate in a critical way the discipline he mastered more [6]. In short, the mission of higher education requires a pedagogue whose development is as complete as possible. The in-depth learning of a discipline, that is, its specialization, must in no way prevent it, on the contrary, from opening itself to other modes of knowledge, understanding or transformation of reality .It is this openness that will enable it eventually to continue with his students transdisciplinary training objectives, such those basic skills which will be discussed further, and develop with colleagues interdisciplinary collaborations. Disciplinary competence, then. This disciplinary competence seems unavoidable.

This is the mastery of a discipline, with all that it implies knowledge, skills and attitudes specific to a field of knowledge. It is not without reason that CNRST in universities generally require a master's degree or a doctorate as initial training for the one who has to teach. All master, regardless of specialty, is primarily a master of humanity and culture, certainly. But it is also the master of a particular discipline, he could deepen, he seized the ideological, historical and methodological. This mastery allows him, ultimately, contribute to the advancement of the discipline, producing himself useful and meaningful knowledge.

Didactic competence, also Higher education requires, in fact, this fundamental aptitude which allows the teacher to lead the student to master the object and the approach of a discipline [4]. The didactic competence lies in the art and the science which consists in training the student to gradually take over the ideological and methodological foundations of a discipline. It is this which introduces into the very logic of a discipline, its constitutive object and its tried and tested method. The didactic competence therefore presupposes that one is well trained in one's discipline and that one has mastered the epistemological approach in order to be able to communicate it. For this is the communication of a discipline, which relates the thought and the method of this discipline to the pedagogical activity of the teacher and the learning activity of the student.

Finally, pedagogical competence. This is the process of helping, properly speaking, and the student to learn and develop. The actual teaching competence therefore lies primarily in the quality of the relationship between the teacher and the student and it assumes that the teacher understands how students can move toward mastery of the subject and method of discipline. In this sense, pedagogy uses a psychological and sociological knowledge of those who learn, has an understanding of their learning styles and their mental processes, while teaching refers more to the art of communicating and transmitting epistemological approach to discipline [2].

The teacher acts not only as a communicator and as an expert in a given discipline, but more as a pedagogical educator, as a witness to scientific, intellectual, moral, social and cultural values. At the level of higher education, as at other levels, the relational dimension is important and does not constitute a student caprice. The competent pedagogue is also the one who master the three main phases of the pedagogical activity: planning, organization and evaluation. Planning refers to the objectives to be achieved; the organization refers to the means, methods and strategies used; the evaluation concerns the verification of student learning, but also calls for a critical return 
on the pedagogical activity itself [5]. It is through this set of competences that the teacher can take on the complementary dimensions of his pedagogical activity in higher education .

At this level, pedagogical activity is, above all, an activity that cultivates. If higher education still persists has to define itself as a place of organized knowledge, but constantly changing, as the perfect place and form the intellectual and critical scientists society as a medium or exercise the critical function and the pursuit of research which contributes to the progress of the community, it is necessary that the pedagogues who work there should become aware of the necessity of cultivating minds and of procuring them that versatility which opens up all fields of culture [7]. The educational activity in higher education is an activity that cultivates, certainly, but it is also an activity that specializes. To specialize is to bring to the mastery of a discipline and, especially to higher education, the very foundations of a discipline. It is in turn leading the student towards a disciplinary competence. It can be seen that it is the mission of higher education, taken here from the angle of culture and specialization, which imposes on the teacher the cultural, disciplinary, didactic and properly pedagogic competences mentioned above.

\section{The pedagogy of fundamental training}

The basic training is a hub of education at the college and undergraduate university. It integrates, in a way, the two complementary concepts of general training and specialization [8]. It is therefore with reason that it is more and more a frame of reference which it is important to clarify, no doubt, but which will also focus on clarifying the major issues properly pedagogical.

\subsection{Basic training as a framework}

Reflections on basic training are presently numerous and reflect both the need to clarify the notion, the desirability of identifying the implications and the relevance of showing its fertility. Five characteristics of basic education in the pre-university and technical college and undergraduate sectors are noted here. The first characteristic is that fundamental training aims at the integral development of the person, that is, it overlaps the so-called cognitive, socio-affective and psychosocial. In addition to developing its intellectual power, the student continues the affirmation of identity, the quality of interpersonal relationships, successful social integration, wider and deeper self.

On this side, the basic formation joins the liberal and humanist formation and includes an undeniable general formation, which both pursues the opening to several fields of knowledge [6]. Second characteristic: basic training necessitated, college and university levels, an anchor in a field of knowledge or expertise. This rootedness in a field of meaning is typically a choice of orientation and traces the path towards the planned specialization: pure sciences, humanities, arts, humanities, physical techniques, biological or administrative, for example, in college. Through this anchor, the 
student explores a type of approach to the real, privileged a point of view on which he concentrates his mind, learns a particular language and has a way of apprehending reality [8]. The third characteristic is that fundamental training is the foundation. Starting from a type of approach to reality, she continued the mastery of basic concepts, historical landmarks, and methodical approaches. Allowing access to the philosophical, epistemological, historical and methodological foundations of a field of knowledge, it opens on transdisciplinarity; it retains, to a significant extent, the instrumental aspect of a discipline that leads to the development of basic skills: asking and solving a problem, analyze, synthesize, clarify values, for example.

A program inspired basic training therefore not only specified the essential content to acquire, but also the skills, abilities and basic skills has mastered, through disciplines. And among these capacities and skills exist, primarily, those that allow the critical review of the approach used, the development perspective of the operations or the objectification of an intellectual process. This is what some call the 'metacognition' and which manages an authentic basic training [9]. Fourth characteristic: basic training implies coherence. It takes place on the basis of organized and integrated knowledge. It is based on disciplinary coherence and pursues systematic and unified learning. In this sense, it calls for the integration of the objectives of a field of technical training, pre-university or university.

It requires the convergence of teaching and the internal coherence of training. Fifth characteristic; the basic training allows the feasibility traits of the learning. Aiming at access to the foundations of a field of knowledge, it promotes the transfer of basic knowledge, skills and attitudes to other areas of knowledge and even to new situations imposed by life. It therefore makes the student able, at least in principle, to make connections with other types of approach to reality, to open to other languages and apply their learning to new situations. In this sense, it introduces the opening in the specialization; it contrasts versatility with utility, transferability with the sharpness of knowledge and creativity with pure and simple execution.

\subsection{The pedagogical tasks required by basic training}

Basic training has its own pedagogical requirements. There is an 'interface' between basic education and pedagogy which must now be clarified. In short, the fundamental education imposes tasks which are carried, strictly speaking, the pedagogical activity itself. It presents here five that seem major. The first task is to rely on students' commitment to their own training and qualification. Because it is an integrated development that includes assertiveness and personal autonomy and because it leads to the transferability of learning and creativity, basic training requires the active participation of students. The pedagogy must allow, through various methods, laboratory work, essay writing, personal research, cooperative learning, seminars, etc. This student engagement in a path of fundamental training. The second task is open disciplinary practice. From the perspective of basic training, teaching a little discipline do more to close in on itself [10]. No discipline can then be taught as a closed universe in itself. On the contrary, at the heart of the pedagogical activity must be identified its 
links with other disciplines, its relationship with other approaches to reality and its place in the universe of culture.

An open disciplinary practice thus requires breaking down disciplinary barriers. We can understand how this openness to other disciplines demands, in the professor, the cultural competence mentioned above; it also asked him to go beyond the disciplinary grid to the level of the basic training aim and the training objectives of the program. Ultimately, the overall objectives of the program and the teaching approach are inextricably subsequently assembled. The third task requires that the pedagogue help to move towards the foundations of the discipline. It is therefore necessary to identify the pedagogical strategies that help students to identify the subject of a discipline, to grasp its spirit, to experiment with the methodical approach and to master the key concepts.

This presupposes that we have first understood the specificity of his discipline and the nature of his contribution to the formation of intelligence and to the development of the person: this also makes use of the disciplinary competence and didactic competence evoked above [7]. The fourth task places emphasis on essential learning at the center of the pedagogical activity. In this sense, the teaching of the discipline is clearly directed towards the acquisition of a fundamental formation, that is to say, of the knowledge, skills and attitudes which form the intelligence and develop the person. Insist on the acquisition of a historical sense, the rigor of reasoning, the mastery of a concept and its application to new situations is situate the educational act in the axis of essential learning that is the basic training. It is important to identify these learning at the outset, even before choosing the appropriate educational activities and the means of evaluation that will enable us to verify their achievement. The fifth task is to promote the integration of learning [4].

The pedagogical activity takes the path of fundamental formation when it allows the student to integrate all his learning, which is to say to organically retain them and transfer them to various situations. Indeed, a relevant pedagogical practice leads the student to root in himself his various learning by making connections between them, on the one hand, and to establish relationships between his learning and life, on the other hand. It promotes the integration experience, for example, on topics involving knowledge and skills that refer to several disciplines or by the application of knowledge and skills in various contexts or life situations.

\section{$4 \quad$ Pedagogy of the program approach}

Any framework, including training to higher education, can remain relatively theoretical and abstract. To enable basic training to take place, it is necessary to clearly and precisely determine the objectives of the curriculum [11]. It is in this vein that, in college education, for example, the curriculum is defined as 'an integral set of courses leading to the achievement of general and particular training objectives'. And it is in this sense also that it is possible to mention, for higher education, pedagogy required by the program approach. 


\subsection{An organic approach to programs}

The program approach requires for its implementation, an educational vision and program management. It assumes that a training perspective is adopted by program and that this training is interpreted as a basic training. It also requires that, in this process, it sets the general objectives of education; it promotes disciplinary delimitation and adjusted structures, maintaining focus on the consistency of training and the integration of learning. This shows that the program approach, which calls into question deeply rooted structures and practices, remains itself a task to be accomplished. In its essence, so to say, the fact that from the anchor point of a field of knowledge it pursues the acquisition of epistemological foundations and the integral development of the person, the fundamental education comes as the true repository of the program approach. In a sense, it is the royal road of basic training. In other words, the basic idea behind the whole idea of a program approach is fundamental training [12].

It is for this reason, for example, that the regulation on the pedagogical regulations of colleges constitutes the basic principle of the integrating principle of the components of the curriculum. It is in this sense also that, at the undergraduate level, we talk about the need to break down barriers between subjects teaching and to encourage better integration of knowledge. There is continuity between the aims of basic training of the CNRST and those of the first university cycle [13]. This program reference to basic training is, in short, the first dimension of a pedagogical management based on the program approach. The second dimension of this pedagogical management concerns the general objectives of the programs.

The program approach requires that, at the level of the government or at the institutional level, at least the curriculum must be built, the general objectives of the curricula must be clearly defined, and the teaching of the disciplines must lie within this trajectory. In short, these general objectives establish program logic or, more properly speaking, a perspective of training by program, in which each discipline is invited to situate itself. Apart from the fact that these objectives call for the open aspect of the disciplines, that is to say, their ability to acquire transdisciplinary skills such as analysis, synthesis, problem solving, they establish a consistent focus on the students training project. However, it is not possible to clarify the general objectives of the programs or to pave the way for coherent programs simply by piling up requirements of subjects or disciplines; rather, it is by emphasizing the methods and processes, the modes of access to understanding and judgment that must characterize all forms of study [9].

The third dimension refers to the deregulation of disciplines. Breaking down disciplines also means questioning the closure of any course or department. It is recalled that the subjects taught were, for a large part of themselves, an instrumental character, given the training objectives of the program. It should also be pointed out that the isolation of teachers and departments must be exceeded and that everyone is called upon to open up to interdisciplinary exchanges and pedagogical collaborations within a program. As we can see, the program approach does not require that we destroy the structure of disciplinary membership that is the department. Rather, it requires that, if fundamental training is to be updated as a frame of reference, disciplines open up to 
each other and teachers are engaged in a single program. In this sense, the program approach is certainly difficult to achieve fully. But the fact remains that without it, the fundamental education is likely to remain relatively theoretical and abstract [8]. The fourth dimension relates to the effective management of an educational links with the general objectives of the program.

The program requires, in fact, a whole set of management elements functionally subsequently assembled to each other: planning time and spaces. Enable collaborations and consultations needed among teachers; analysis of course outlines in the context of curriculum-based training; structures for disciplinary exchanges; provides support to education by program managers; evaluation and revision of curricula with a view to general objectives whose main focus is fundamental training. In short, what needs to be ensured is the very timid institutional functioning of the program approach. The fifth dimension of this pedagogical management of programs concerns the learning of the student.

Program coherence and continuity even that may exist between the college and the university finally serving the consistency of training and integration of knowledge in students. The program approach makes the curriculum the foundation of integrated training for the student. Institutional coherence is here to serve the personal integration. Any pedagogical, organizational or curricular measure must never lose sight of its primary meaning: in-depth and integrated training for the student, ie quality training [7].

\subsection{A planning of the pedagogical activity}

In order to be fully realized, the program approach requires, in addition to this organic program management, that the pedagogical activity itself is literally imbued with it. Certainly, planning educational activity includes, for example, the reference to the purposes and objectives of the programs or the knowledge and consideration of enrollment. But it may be thought that the syllabus or curriculum can be one of the most important moments in the implementation of the program approach and one of the most important tools for pedagogical planning, the relationship between the consistency of a training program and personal integration of knowledge [14]. It is in the curriculum always assuming that the curriculum is part of an educational contract that we take seriously and we seek to implement that can be defined in detail the objectives training targets.

This can be expressed first and foremost by the student and the teacher as well as the institution, the link between the general objectives of the program to which the student enrolled, the specific contribution of the discipline to the training targeted and the project of training of the student. It is also possible to highlight the essential learning to which the teaching of the discipline contributes, with a view to fundamental training. It is in the curriculum that one can also explain the pedagogical strategy that one intends to implement to achieve the objectives pursued. If fundamental and program-based training is truly a part of the teaching of the discipline, the pedagogical methods themselves will be 'congruent' with the intended objectives. Thus, for example, lectures may focus on the acquisition of an organized knowledge, a supervised 
practice may continue the development of intellectual skills, and a seminar may encourage an attitude of personal commitment [7]. It is in the curriculum as we can introduce a variety of assessment practices of learning that allow; they also monitor the achievement of basic education goals.

The assessment, formative or summative, is part of the educational activity and must of course be planned in relation to the objectives pursued. An evaluation adjusted from the perspective of basic training is directed towards the verification of broad and complex learning. The curriculum, ideally designed as a tool of the program approach, thus also appears as part of the public education contract between the institution, the teacher and the student. It provides, in a way, the relationship of: basic training objectives of a coherent program, in which the institution must ensure; the contribution of the discipline achieving these objectives, which reports to the teacher; the student's training project [10]. Once accepted by all stakeholders, it constitutes an essential clause of an educational contract that engages the responsibility of the partners. In this sense, the curriculum, being one of the means or expressing a concrete and public way of planning educational activity, can be a prime example of the basic curriculum and training approach.

\section{The pedagogy of research}

It belongs to the college and undergraduate certainly develop the spirit of inquiry. But it is one of the essential aspects of post-graduate studies to ensure the training of researchers. And it also requires an appropriate educational practice, what we call here a pedagogical research [18].

\subsection{The training of researchers}

University and college research were mentioned earlier. What is important to say here is that second and third university cycles pursue, as one of their essential aims, the training of researchers. This is to say that they have as task to lead the students to practice this systematic approach which leads to the production of new knowledge [12]. Masters and doctoral theses memories are obviously a special place for the implementation of such an approach. In any case, at this stage, the training path is inextricably linked to the practice of research [19]. But the CNRST and the undergraduate university must also initiate gradually into this practice of research. Thus, some college technical programs as they require work graduation applied research projects.

Similarly, teaching in the pre-university sector of college and undergraduate university also often involves learning activities that cultivate the spirit of research. If the university, in particular, intends to assume the challenge of training young scientists needed by the company, it must train researchers and intellectually equip students so they can pursue for themselves the various forms of research fundamental or applied, and so that they may also, in their professional practice, keep themselves up to date and apply the results of research in their field [13]. In this sense, if academic freedom of professors still keeps social relevance, it is when it is related to the training of sci- 
entists and development of researchers. We are then far from the individualistic withdrawal, the refusal of control or the flight of any form of coordination, to which it is sometimes identified. Academic freedom does not find real legitimacy if it contributes to the training of young scientists, able to decode the facts, a judge has locate in perspective and offer new readings of becoming, if not new Controller or the ways to transform reality.

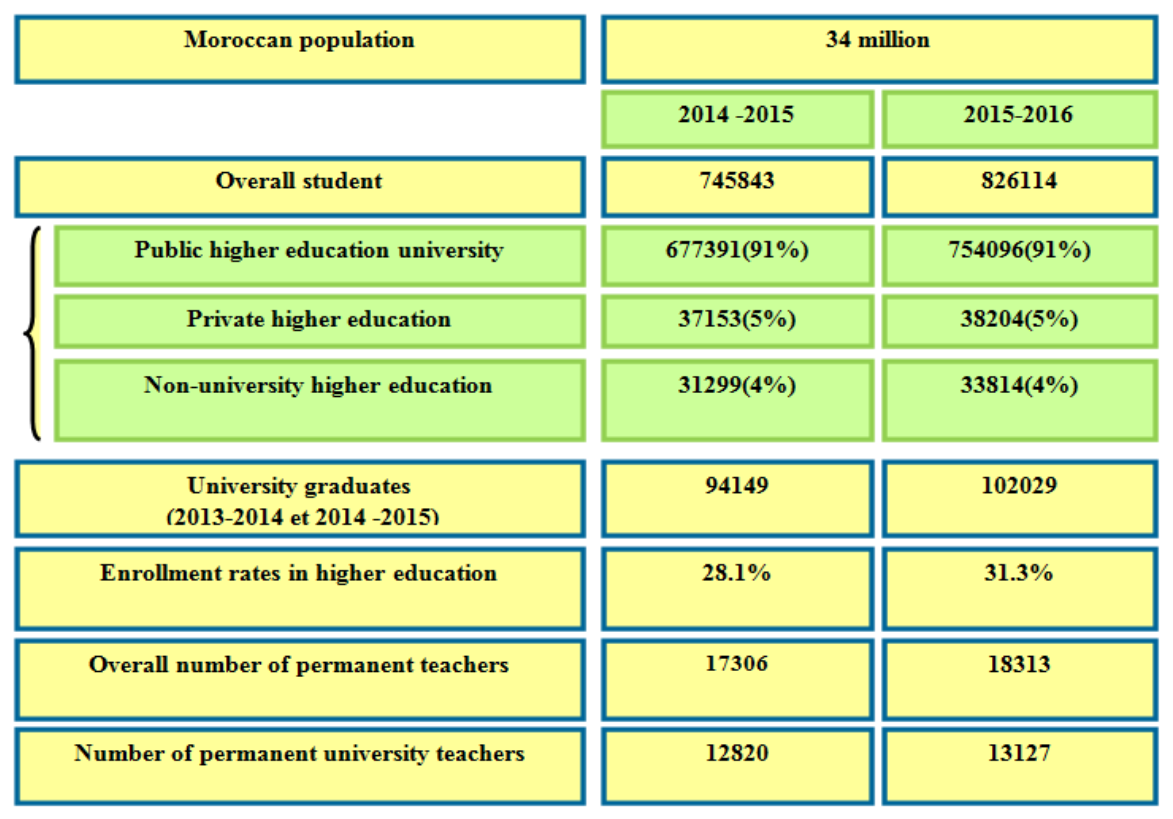

Fig. 2. Higher education in Morocco, key figures

\subsection{The didactic creativity}

The great challenge of pedagogy of research lies in the ability of the teacher to awaken the student's creativity resources in the field of knowledge and expertise. This assumes that the master himself 'mastery' in fact, has a high degree, the methodical approach of research in its own discipline. Indeed, it must first cultivate in the student the spirit of research. Such a spirit of research is a provision that must be emphasized in a didactic of creativity. Even more radical than the methodical spirit, it takes root in the desire to know itself and presupposes astonishment, without which no intellectual step takes life itself [11]. The didactic creativity presupposes that fits the student through various formulas in a research project. The desire to know small then associate with the methodical approach.

Research also requires conducting a methodical approach. It is carried out seriously if the student takes a systematic, organized, and rational. And what grounds such an approach, it is a spirit, an attitude or disposition that encourages proceeds with order and precision. This is an essential step; the master himself must follow on the road 
that leads to creativity [8]. But, moreover, the didactic of creativity cultivates, inseparably, the disciplinary and interdisciplinary spirit. There is nothing chauvinistic in this, for what is at first a confrontation of the student with the very object of a discipline and the systematic approach that this objects to be seized. It is then at the very heart of a discipline or, to put it differently, in its foundations. We can see from this the extent to which the development of this disciplinary spirit [12] corresponds to the aims of the fundamental formation of which we have spoken above.

Moreover, the interdisciplinary spirit brings to the research the cultural openness that ensures it both a deep rooting and a necessary perspective. In total, therefore it is to cultivate the various dimensions of the same creative spirit. Desire for knowledge, methodical approach, and object disciplinary and interdisciplinary openness are here inseparable. The desire to know borrows the approach imposed by the disciplinary subject and object disciplinary awakens the desire of systematic research, while opening interdisciplinary stimulus ever desire to know. And this is what the teacher must bear in his teaching and his research. Such is the teaching of creativity required by a pedagogical research [18].

\section{Organization of the Higher Education System: Case of Morocco}

The Moroccan higher education system consists of three main areas [20]:

- Public higher education

- Higher education in the framework of the partnership

- Private higher education

Public higher education includes [21]:

- Universities: these are public institutions under the supervision of the Ministry of Higher Education, Scientific Research and the Training of Executives. The Kingdom currently has twelve (12) public universities and private management for public university spread over different parts of the country.

- The Institutions of Higher Education does not Relevant Universities: these are specialized higher education institutions under the administrative and financial supervision of ministries and in the teaching authority of the Ministry of Higher Education, Research Scientific and Management Training [22].

- The universities and institutions set up within the framework of partnership are non-profit foundations created within the framework of the dynamics of internationalization of Moroccan higher education. These universities and institutions are under the pedagogical authority of the Ministry of Higher Education, Scientific Research and Training of Managers [23].

- Private higher education includes universities and institutions created by private initiatives but under the pedagogical authority of the Ministry of Higher Education, Scientific Research and Training of Managers [24]. 


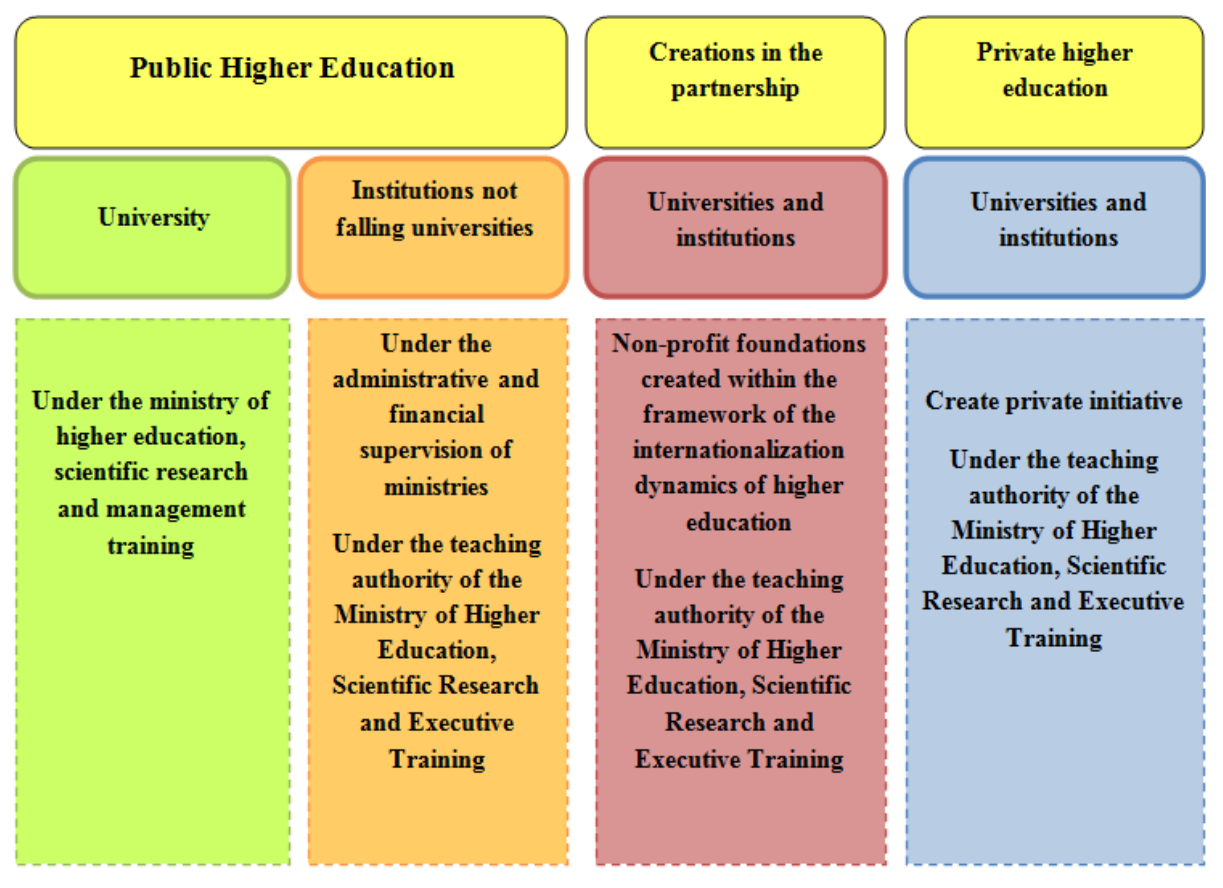

Fig. 3. Overview of Higher Education in Morocco
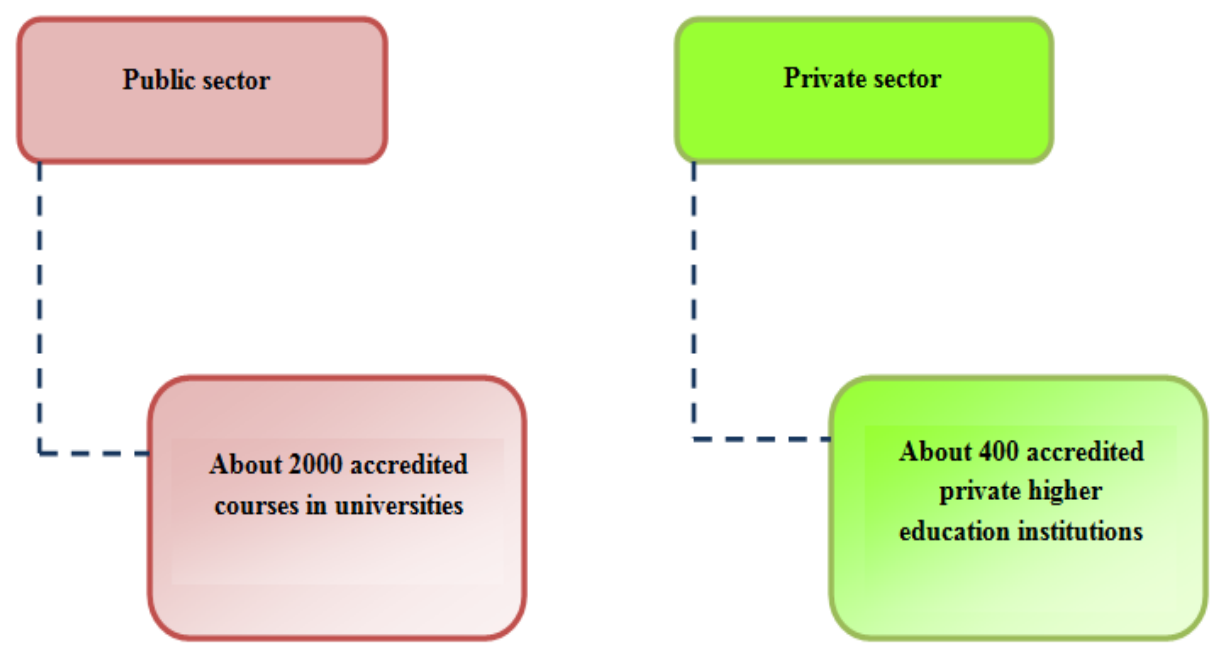

Fig. 4. Higher education between the public and private sectors 


\section{Conclusion}

The training mission of higher education, we have seen, calls from within itself, appropriate teaching practices. They have been called pedagogy of higher education, pedagogy of basic training, pedagogy of the program approach and pedagogy of research. But, on the whole, what emerges here is that a training mission contains, in its very essence, a pedagogical requirement. Pedagogy is one of the major challenges of higher education today, which imposes on the educators concerned a four-fold competence, cultural, disciplinary, didactic and pedagogical, and that these aspects are complementary and inseparable dimensions of the pedagogical activity. Higher education institutions, recognizing the fundamental training as a framework, are concerned to explain the educational requirements of students undertaking practice of interdisciplinary, assistance journey to the fundamentals, focus on essential learning, integration of learning and make each has the necessary support. Educational institutions, adopting the perspective of the program approach, see what it has on the planning of the educational activity, the curriculum of which constitutes both a witness and an essential tool. Educational institutions including universities, aware of their mission to ensure the scientific and technical reports, encourage teachers implement instructional creativity, cultivating the spirit of research, methodical spirit, disciplinary and interdisciplinary spirit.

\section{Acknowledgment}

Thanks to the Ministry of National Education, Vocational Training in Higher Education and Scientific Research, State Secretariat for Higher Education and Scientific Research in Morocco and National Center of Scientific and Technical Research (CNRST) of Morocco

\section{References}

[1] Kettunen, J, Strategy process in higher education, Journal of Institutional Research, Vol. 15 No. 1, pp. 16-27,2010

[2] Nusche, D, Assessment of learning outcomes in higher education: a comparative review of selected practices", in OECD Education Working Paper No. 15, OECD, Paris, 2008.

[3] Jan McArthur , Time to look anew: critical pedagogy and disciplines within higher education, Studies in Higher Education Vol. 35, No. 3, 301-315, May 2010 https://doi.org/10.1080/03075070903062856

[4] Joan M. Nicoll-Senft and Susan N. Seider, Assessing the Impact of the 4MAT Teaching Model Across Multiple Disciplines in Higher Education, COLLEGE TEACHING, 58: 1927Copyright C Taylor \& Francis Group, LLC ISSN: 8756-7555 print, 2010 https://doi.org/10.1080/87567550903245623

[5] Kolb, D. A., \& R. E Boyatzis. 1993. Learning skills profile. Boston, MA: McBer \& Company 
Paper-The Pedagogy of Higher Education: How to Evaluate the Quality of Training in Morocco to ...

[6] Kotsiantis, S.B. \& Pintelas, P.E. (2005), Predicting Students Marks in Hellenic Open University, ICALT 2005. Fifth IEEE International Conference on Advanced Learning Technologies, Kaohsiung, pp. 664668 https://doi.org/10.1109/ICALT.2005.223

[7] Behrouz, M, Karshy, D, Korlemeyer G, Punch, W. Predicting student performance: an application of data Mining methods with the educational web-based system, Lon-capa. 33rd ASEE/IEEE Frontiers in Education Conference. Boulder C.O. USA, (2003).

[8] Sai Loo, Jill Jameson, Vocationalism in Further and Higher Education Policy, Programmes and Pedagogy ,Routledge, 2017.

[9] Arkoudis, S., Baik, C., \& Richardson, S. (2012). English language standards in higher education. Melbourne, Australia: Australian Council for Educational Research. Doughney, L., Ewen, S., Arkoudis, S., \& Delany, C. (2016).

[10] Clewes, D, A Student-centred Conceptual Model of Service Quality in Higher Education. Quality in Higher Education, 9(1), 69-85, 2003 https://doi.org/10.1080/13538320308163

[11] Halai, N, Quality of private universities in Pakistan: An analysis of higher education commission rankings 2012. International Journal of Educational Management, 27 (7), 775-786, 2013. https://doi.org/10.1108/IJEM-11-2012-0130

[12] Falih M. Alsaaty, Ella Carter, David Abrahams \& Faleh Alshameri, Traditional Versus Online Learning in Institutions of Higher Education: Minority Business Students' Perceptions, Published by Scie du Press, Business and Management Research ,ISSN 1927-6001 E-ISSN 1927-601X, Vol. 5, No. 2; 2016

[13] Sofia Bounahai, Higher Education In Morocco, University Of Essex, January 17, 2014

[14] El Bachir Kouhlani, Reform of Higher Education in Morocco Achievements and Perspectives, Grenade 05/10/2011.

[15] Santhiram Raman, Emerging Trends in Higher Education Pedagogy, ISBN 978-983-3910$03-8,2016$

[16] Rafiq, M,Voyage dans le système éducatif marocain depuis l'université Quaraouyine jusqu'à l'ère du numérique : historique et rôle dans la civilisation, Académie des Sciences et Lettres de Montpellier Conférence du 22 novembre 2010 Académie des Sciences et Lettres de Montpellier, 2010.

[17] Ahmed MEZIANI, The system of higher education in MOROCCO: A brief introduction report, Mediterranean Journal of Educational Studies, I Vol.4(2\}, pp.215-219, 1999

[18] H. Slimani, N. El Faddouli, R. Benslimane, S. Bennani, "Personalized search and recommendation in a digital educational resources repository: The case of ORIOAI", Information Science and Technology (CiSt) 2016 4th IEEE International Colloquium on, pp. 541-546, 2016, ISSN 2327-1884.

[19] Bouchaib Riyami, Khalifa Mansouri, Franck Poirier. Towards Integrating Mooc In The Moroccan Higher Educational System: Economic Pedagogical Model Based On Ict For On-Going Education And Teacher Motivation. Iceri 2016, Nov 2016, Seville, Spain. 1, Pp.6867 - 6873, 2016.

[20] www.enssup.gov.ma

[21] A. Ghouati, Réforme LMD au Maghreb : éléments pour un premier bilan politique et pédagogique, JHEA/RESA Vol. 7, Nos. 1\&2, 2009, pp. 61-77

[22] ABSTRACT TWINNING PROJECT "Support to the Higher Education system in Morocco within the framework of a rapprochement with the European Higher Education Area" June 2017 - Kingdom of Morocco (www.enssup.gov.ma)

[23] H. Slimani , N. El Faddouli , R. Benslimane, S. Bennani, The normalization of the indexation of digital educational resources for higher education among the Arab countries: the case of Moroccan application profile, This paper is available on International Journal of 
Paper-The Pedagogy of Higher Education: How to Evaluate the Quality of Training in Morocco to ...

Information Technology \& Computer Science ( IJITCS ) ( http://www.ijitcs.com ) (ISSN : 2091-1610) on volume No : 22, Issue No : 1

[24] M. Ouzarf , the facts and challenges of moroccan digital university - Regionalization and Local Development. ICT in local communities and territorial and socio-economic stakes. [Online]. Available: http://devlocal.over-blog.com/pages/l-universite-numeriquemarocaine-faits-et-defis-2811661.html. [Accessed: 10 February 2015].

\section{Authors}

Sara Riahi received the License degree in Mathematics and Computer Science in 2010, then she received the M.S degree in Software Quality in 2012, from University of Sciences, Chouaib Doukkali, El Jadida, Morocco. She is currently PhD in the Department of Mathematics and Computer Science, Faculty of Sciences, Chouaib Doukkali, El Jadida, Morocco. Her research activities focus on the modelling databases, Big-Data, Optimisation, Dataminig, computer protocols, wireless communication, large-scale multimedia systems, and mobile applications

Professor Azzedine Riahi received his PhD in Nuclear Physics in 1987 CENBG at the University of Bordeaux, France, he graduated in Nuclear Medicine, he is a professor the upper education at university chouaib Doukkali since 1988, he is currently Director of laboratory Instrumentation, measurement and control (IMC).

Article submitted 14 November 2017. Resubmitted 23 December 2017. Final acceptance 05 February 2018. Final version published as submitted by the authors. 